\title{
Desenvolvimento Econômico e Instituições Financeiras em Economias com Moeda Endógena
}

\author{
Economic development and Financial Institutions in endogenous money \\ economies
}

\author{
Nikolas Peçanha Vieira Passos'
}

RESUMO

\begin{abstract}
A relação entre sistema financeiro e desenvolvimento econômico remete aos estudos de Schumpeter e foi resgatada na década de 1990, com o objetivo de justificar a liberalização financeira das contas de capitais e dos mercados domésticos. A problemática ganhou especial relevância após a crise de 2008, quando a instabilidade do sistema financeiro exigiu a intervenção pública para a garantia do crescimento. Neste estudo, analisamos dois argumentos da teoria econômica tradicional: (i) o crescimento do sistema financeiro causa o crescimento econômico (ii) a alocação ótima de recursos financeiros pelo mercado é capaz de causar crescimento pela via da mudança estrutural. Em primeiro lugar, argumenta-se que quando consideramos a moeda endógena, os volumes de finança e moeda são condicionados pela demanda efetiva, portanto, não podem causar o crescimento. Em segundo lugar, os fluxos financeiros teriam um papel relevante para o desenvolvimento na medida em que transferissem recursos para atividades inovadoras, promovendo a mudança estrutural. Por outro lado, ao explicitar as especificidades de tais atividades inovadoras, podemos concluir que o mercado financeiro atuando livremente é insuficiente para alocar recursos na direção de atividades fundamentais para o desenvolvimento.
\end{abstract}

Palavras-chave: Moeda endógena; Mudança estrutural; Crescimento econômico; Instituições financeiras

\begin{abstract}
The relation between financial system and economic development dates back to the studies of Schumpeter and was revived in the 1990's aiming to justify financial liberalization of capital accounts and domestic markets. In this paper we analyze two arguments of traditional economic theory: (i) the growth of the financial system causes economic growth, (ii) the optimal allocation of financial resources by the markets is capable of causing growth through structural change. Firstly, we argue that when we take money as endogenous, the volume of finance and money are conditioned by effective demand, thus it cannot cause growth. Secondly, financial flows have a relevant role for development in the case they transfer resources to innovative activities, promoting structural change. On the other hand, when we specify the characteristics of those innovative activities we conclude that financial market acting freely is not sufficient to allocate resources in the direction of activities fundamental to development.
\end{abstract}

Key-words: Endogenous Money; Structural change; Economic growth, Financial institutions 


\section{INTRODUÇÃO}

Mudança estrutural pode ser entendida como mudanças de longo prazo na composição dos agregados econômicos (Kruger, 2008). Tais mudanças implicam o crescimento mais acelerado de algumas indústrias, alterando a parcelas de tais indústrias no agregado total. Duas causas são centrais para as mudanças estruturais: as elasticidades renda da demanda e os impactos do progresso tecnológico. $O$ progresso tecnológico afeta a mudança estrutural na medida em que indústrias menos produtivas tendem a encolher sua participação no produto total da economia. Tal padrão tende a atuar como promotor do crescimento da produtividade agregada. Isto é, por meio da alteração da composição setorial da economia, a produtividade agregada pode crescer, mesmo que não haja aumento da produtividade das indústrias individuais. Por meio de tal efeito na composição a mudança estrutural afeta o crescimento econômico.

Para que a mudança estrutural ocorra, ativos imobilizados são transformados em ativos mais líquidos e transferidos para outro setor ${ }^{1}$. A ligação entre o estoque de capital físico disponível em um setor menos produtivo (e cuja produção é declinante) e o capital físico do setor onde este capital será realocado é feita por instituições financeiras. O capital enquanto finança é necessário para habilitar indústrias mais produtivas a levarem a cabo suas estratégias de investimento. Na medida em que indústrias dos setores mais produtivos não disponham de capital para realizar investimentos, instituições financeiras as habilitam, caso tenham confiança no financiamento.

É nesse sentido que Schumpeter (1961) afirma que as finanças autorizam o empreendedor a inovar. A teoria do desenvolvimento econômico de Schumpeter é baseada na ideia de que a introdução de inovações no mercado (sejam elas de produtos, processos, etc) cria empresas mais produtivas, as quais substituirão empresas antigas, menos inovadoras e menos produtivas. Instituições financeiras seriam essenciais para tal processo, pois, além de intermediar o fluxo financeiro entre os possuidores dos meios produtivos e os empreendedores, as instituições financeiras (na figura do banqueiro) seriam capazes de produzir poder de compra, ao emitir crédito não inteiramente lastreado, autorizando as novas combinações (Schumpeter, 1961, p 80). Na medida em que os bancos seriam condição necessária para que o empreendedor se tornasse capaz de inovar, o desenvolvimento, entendido como processo de crescimento econômico com mudança estrutural, seria impossível sem o crédito.

A partir das contribuições originais de Schumpeter, a literatura econômica evoluiu no sentido de esclarecer outros mecanismos teóricos pelos quais as instituições financeiras colaboram para o desenvolvimento econômico. 0

\footnotetext{
${ }^{1}$ Neste artigo utiliza-se os termos indústria e setor de forma intercambiável, significando um "grupo de empresas voltadas para a produção de mercadorias que são substitutas próximas entre si e, dessa forma, fornecidas a um mesmo mercado", usualmente tais empresas "operam métodos produtivos semelhantes, incluindo-se em uma mesma base tecnológica" (Dantas et alli, 2013, p.21).
} 
desenvolvimento das instituições financeiras foi apontado como causador de uma maior taxa de acumulação de recursos e de um emprego mais adequado de tais recursos. Defendeu-se, então, que o desenvolvimento financeiro propiciava o desenvolvimento por possibilitar uma quantidade maior de investimentos e uma qualidade melhor de tais investimentos.

Neste artigo analisam-se dois argumentos sobre a capacidade do sistema financeiro em promover o desenvolvimento econômico: a capacidade de o sistema financeiro afetar o volume de investimentos e sua capacidade de afetar a qualidade dos investimentos. Além desta introdução, o artigo se divide em quatro seções. $\mathrm{Na}$ segunda seção é apresentada a literatura sobre finanças e crescimento, expondo alguns resultados empíricos e as dificuldades teóricas e empíricas em se lidar com tal tema. Na terceira seção, apresenta-se a contribuição do modelo McKinnon-Shaw, à qual é contraposta às contribuições pós-keynesianas e evolucionárias, para explicitar a função das instituições financeiras no aumento da quantidade dos investimentos. $\mathrm{Na}$ quarta seção, apresentamos os mecanismos que apresentam o mercado financeiro como indutor de maior qualidade aos investimentos, especialmente investimentos inovadores. Ressaltamos ainda as dificuldades encontradas por firmas que investem em inovação e as implicações de tais dificuldades para a obtenção de financiamento externo.

\section{ASPECTOS TEÓRICOS E EMPÍRICOS DA RELAÇÃO ENTRE SISTEMA FINANCEIRO E CRESCIMENTO ECONÔMICO}

Ao pressupor mercados sem imperfeições, a análise econômica convencional pode dispensar os efeitos das instituições financeiras sobre a dinâmica agregada real. Considera-se que em um mercado perfeito, o crescimento econômico seria guiado apenas pelos fundamentos da economia: pelo estado da tecnologia e pelas preferências individuais. A racionalidade individual otimizadora é suficiente para garantir a exploração de todas as oportunidades disponíveis, considerando toda a informação disponível em qualquer momento do tempo. Modelos de ciclos reais de negócios, por exemplo, se permitem abstrair todo o conteúdo monetário da economia, tratando todas as trocas como se ocorressem entre bens. Lucas (1988) entendia que a importância do mercado financeiro era exageradamente enfatizada na discussão teórica de desenvolvimento econômico. Para o autor, um baixo desenvolvimento das instituições financeiras é um fator limitante no desenvolvimento considerado de forma mais geral, mas seus efeitos seriam secundários e não estariam claras as consequências da inclusão do sistema financeiro em seus modelos (Lucas, 1988, p 6).

Em geral, em modelos baseados na abordagem de equilíbrio geral de ArrowDebreu em que não há custos de informação e de transação, o sistema financeiro se torna dispensável. Uma vez que a própria necessidade da existência de intermediários financeiros é questionável, é de se esperar que seus efeitos sobre o crescimento sejam nulos. Apenas por meio da introdução de fricções em tais 
modelos é possível justificar a existência do sistema financeiro e observar seus efeitos sobre a taxa de crescimento. A literatura de crescimento econômico baseadas no modelo de Robert Solow ou de crescimento endógeno utiliza tais fricções, especialmente assimetrias de informação, para justificar a existência do sistema financeiro e seus efeitos sobre o crescimento.

A mais frequentemente citada revisão de literatura sobre a influência das finanças no crescimento econômico é assertiva ao afirmar: "We are far from definitive answers to the questions: Does finance cause growth, and if it does, how?" (Levine, 2005, p 868). Apesar de considerar que as respostas não são definitivas, Ross Levine (2005) interpreta que as pesquisas econométricas existentes sugerem que: (i) países com bancos e mercados mais funcionais crescem mais rápido, e tal crescimento independe do país ter seu sistema financeiro baseado em bancos ou em mercado de capitais; (ii) tal efeito não seria oriundo de variáveis omitidas; (iii) sistemas financeiros mais funcionais relaxam restrições ao financiamento externo à firma que impediria o crescimento industrial e das firmas.

Há que se ressaltar as dificuldades empíricas em evidenciar tais links entre crescimento e desenvolvimento financeiro. Como apontam Rajan e Zingales (1998) medidas de desenvolvimento financeiro que considerem apenas o tamanho relativo dos estoques de crédito e do mercado acionário podem estar mensurando, na verdade, o próprio crescimento futuro da produção, o que não revelaria nenhuma causalidade relevante. Ademais, a relação de causalidade é dificilmente evidenciada por meio das estimações de séries cross-section ou em painel, dadas as conhecidas existências de causalidades reversas, simultaneidade, ou viés de seleção.

Além das dificuldades das estimativas macroeconômicas, Arestis e Demetriades (1997, p 14) argumentam que o resultado econométrico positivo entre as finanças e o crescimento não é significativo se considerarmos diferenças nas instituições financeiras de cada país. A hipótese de que instituições financeiras diferentes são necessárias para contextos nacionais específicos remonta à contribuição de Gerschenkron (1962). Para este autor, o atraso relativo das economias teria exigido de países em desenvolvimento retardatário (como Alemanha e Rússia) instituições financeiras mais centralizadas, capazes de coordenar a produção de forma mais próxima. O desenvolvimento financeiro seria este mesmo condicionado pelo grau de atraso relativo.

A relevância das diferenças institucionais é enfatizada também no trabalho de Zysman (1983) que divide os sistemas financeiros (ou as variedades de capitalismo) nacionais em três grandes categorias: (i) crédito guiado pelo governo; (ii) crédito bancário e (iii) mercados de capitais. A partir das distinções propostas por Zysman diversos estudos avaliaram quais tipos institucionais têm melhor capacidade de promover o desenvolvimento econômico. Dosi (1988) apresenta uma discussão teórica que distingue entre sistemas baseados em mercado e sistemas baseados em crédito, mas argumenta que não é possível estabelecer uma relação simples e unívoca entre as eficiências reveladas por cada um dos sistemas com o propósito de promover atividades inovadoras. 
Além dos problemas dos trabalhos empíricos e da dificuldade de sistematização das questões institucionais, resultados recentes apontam para a não linearidade da relação entre o tamanho do sistema financeiro e crescimento econômico. Arcand, Berkes e Panniza (2012) relatam que o crescimento do setor financeiro pode afetar negativamente o crescimento do produto quando o estoque de crédito do setor privado atinge $100 \%$ do produto nacional. Law e Sighn (2014) proveem evidências adicionais da existência de um limite para os efeitos positivos do crescimento do sistema financeiro sobre o crescimento econômico. Nos dois trabalhos, apontam-se alguns complicadores para a relação entre finanças e crescimento, como o risco crescente gerado por um mercado financeiro maior que o produto nacional.

Especialmente após a crise de 2008, evidenciou-se a não validade da máxima defendida até a década de 1990 de que quanto maior o sistema financeiro, maior o crescimento econômico. O desenvolvimento do sistema financeiro não pode ser entendido apenas como o crescimento dos estoques de crédito e do tamanho do mercado de ações, mas é melhor entendido como uma maior capacidade em cumprir suas funções. Studart (1995) considera um sistema financeiro funcional quando este é capaz de prover financiamento e funding de forma a suportar o desenvolvimento sem aumentar substancialmente a fragilidade ou iliquidez do sistema financeiro.

Como ressaltado por Jan Kregel (2013) e enunciado incialmente por Hyman Minsky, há um paradoxo entre a função do sistema financeiro como sistema de pagamentos e como financiador do desenvolvimento. Por um lado, o sistema financeiro recebe depósitos e os mantêm disponíveis para a efetivação de trocas financeiras seguras. Por outro, tem a função de financiar empreendimentos de risco. Conforme argumentaremos adiante, a promoção do desenvolvimento econômico envolve o investimento em atividades cujo retorno é incerto, o que aumenta as dificuldades para a organização de um sistema de pagamentos seguro. Assim, o mercado financeiro deveria ser regulado de forma a lidar com suas duas funções principais, em que se sublinha o caráter fundamental de políticas públicas para o desenvolvimento das instituições financeiras.

Desta seção concluímos que em um contexto de mercados perfeitos não há sentido em perguntar sobre os efeitos do sistema financeiro sobre o crescimento. Os efeitos sobre o crescimento surgem das funções desempenhadas pelo sistema financeiro em processos alocativos sujeitos a diversas falhas de mercado. A separação de tais efeitos pela literatura empírica em nível agregado é dificultada tanto por desafios metodológicos, quanto pela desconsideração de características institucionais. A literatura falha ainda em desconsiderar a crescente tensão existente entre o crescimento do sistema financeiro e a estabilidade dos sistemas de pagamentos. O desenvolvimento do sistema financeiro deve ser entendido em termos de sua funcionalidade, na provisão de um volume adequado de finanças e sua alocação entre atividades mais produtivas.

\section{POUPANÇA, INVESTIMENTO E CRESCIMENTO}


$\mathrm{Na}$ década de 1970, os estudos sobre a relação entre finanças e desenvolvimento se basearam na ideia de que países subdesenvolvidos sofriam com a falta de profundidade do sistema financeiro ou, o que seria mais grave, com a repressão financeira. Para Mckinnon (1973) e Shaw (1973) governos dos países subdesenvolvidos seriam responsáveis pela execução de políticas que limitariam os fundos emprestáveis disponíveis para a intermediação dos bancos, gerando restrições ao financiamento externo das empresas.

Políticas como o direcionamento de crédito, altas taxas de reservas compulsórias, taxas de juros reais reguladas, baixa competição bancária, barreiras à entrada a instituições financeiras internacionais e a existência de bancos públicos impediriam que as taxas de juros reais fossem determinadas pelo mercado, fazendoas se situarem em um patamar inferior àquele de equilíbrio. A repressão financeira seria, assim, uma fricção no funcionamento dos mercados. A liberalização eliminaria tal fricção e permitiria que o mercado fosse conduzido ao equilíbrio paretiano.

$O$ alívio de tais restrições financeiras teria um efeito positivo sobre o crescimento, na medida em que as taxas de juros se elevassem na direção da taxa de equilíbrio. Com a elevação das taxas de juros, haveria um aumento na poupança, na acumulação de capital e uma mais eficiente alocação dos recursos. Assim, a repressão financeira afetaria a quantidade de investimento, por meio da redução da poupança, e a qualidade do investimento, devido à pior alocação de capital.

No modelo proposto por Mckinnon-Shaw é enfatizada a posição do sistema financeiro enquanto propulsor da poupança, por meio da elevação das taxas de juros. A ênfase no volume de poupança remete à clássica discussão acerca da precedência da poupança sobre o investimento, tema recorrente na literatura de finanças e desenvolvimento. A defesa do aumento da poupança como motor do desenvolvimento entende que a poupança (o sacrifício do consumo presente) provê financiamento para a acumulação de capital, o que, por sua vez, gera produção adicional, que pode potencialmente ser utilizado para consumo no futuro (Gersovitz, 1986, p 382).

Os resultados do modelo de McKinnon-Shaw podem ser questionados por, pelo menos, três fatores. Primeiramente, não há evidências de que as taxas de poupança são afetadas positivamente pelas taxas de juros (Stein, 2010, p 301). Em segundo lugar, o aumento das taxas de juros teria efeitos controversos sobre a taxa de investimento: a elevação das taxas de juros leva à redução da demanda, seja diretamente por meio dos bens duráveis e imóveis, ou indiretamente pelos efeitos sobre o estoque de dívida e sobre o investimento. Por fim, o pressuposto inicial de que as taxas de juros se elevariam com o fim da "repressão financeira" é questionável, uma vez que a taxa de juros básica da economia não é determinada como um equilíbrio entre poupança e investimento, mas determinada pela ação política dos bancos centrais (Lavoie, 2014, p 183).

Apesar das diversas falhas, o modelo teórico proposto por Mckinnon e Shaw foi amplamente utilizado pelo Banco Mundial e pelo FMI em sua justificativa para os processos de liberalização financeira na década de 1980 (Carner, 2010, p 224). A 
partir da década de 1990, McKinnon (1993, p 22) reconhece que a poupança agregada não responde às taxas de juros, e aponta que o principal canal por meio do qual a liberalização financeira afetaria as taxas de crescimento seria por meio da qualidade dos investimentos, e não sua quantidade. Isto é, os efeitos do setor financeiro sobre o investimento seriam sentidos por meio do aumento da eficiência na alocação do capital. Não seria o volume de poupança - ou mesmo o tamanho do sistema financeiro - o que garantiria maiores taxas de crescimento.

O modelo original de Mckinnon e Shaw se baseia na teoria dos fundos emprestáveis, em que os intermediários financeiros são captadores de poupança, com a principal função de redistribuí-la a tomadores de empréstimos. A teoria dos fundos emprestáveis é questionada por Keynes, e por Schumpeter (1962, p 82), que concordam sobre o papel ativo dos bancos na criação de poder de compra, e não apenas na redistribuição de poupança. Uma vez que se considera válido o Princípio da Demanda Efetiva, a poupança passa a ser entendida apenas como um fluxo residual às decisões econômicas de gasto, sendo simultâneo e determinado pelo investimento. Como esclarece Possas (1999, p 6) "quem financia o investimento é o crédito, este sim, um estoque - de poder de compra, criado ex-nihilo pelo sistema bancário - que precede lógica e temporalmente o investimento; aliás, costuma ser essencial para viabilizar os investimentos devido à magnitude normalmente elevada desses vis-à-vis às receitas líquidas correntes capitalizadas pelas empresas"

Uma visão contemporânea da criação do poder de compra por bancos se associa à perspectiva da moeda endógena. Se definirmos a endogeneidade da moeda de forma ampla, como a incapacidade de o Banco Central definir a oferta de moeda, podemos afirmar que a endogeneidade da moeda é assumida pela grande maioria dos modelos econômicos contemporâneos sejam eles ortodoxos ou heterodoxos. De uma perspectiva ortodoxa, a contribuição de Woodford (2003) e John Taylor (1993) é notável neste sentido, por esclarecer a atuação dos Bancos Centrais enquanto definidores do preço da moeda (por meio da taxa de juros) e não da quantidade ofertada. Apesar da coincidência deste ponto de vista restrito de endogeneidade da moeda, as visões com a abordagem pós-keynesiana são divergentes especialmente se levarmos em conta as considerações de longo prazo, para o crescimento.

Em uma leitura pós-keynesiana, a capacidade dos bancos em fornecer crédito é, de fato, limitada pela capacidade dos tomadores de empréstimo em se mostrarem dignos de receber crédito (Lavoie, 2014, p 193). Tal capacidade é limitada pelas características dos potenciais tomadores de crédito, pelo volume de colateral (ou demais garantias), e pela preferência pela liquidez dos bancos. Assim, a criação de moeda ex nihilo está, na verdade, sujeita às características da demanda por crédito, isto é, à capacidade do demandante em fornecer colateral. As características do demandante por crédito são fundamentais para compreender o volume de crédito ofertado. Demandantes de crédito com maior risco têm custo de crédito mais elevado e deparam-se com uma oferta escassa. Nesse caso, a demanda por crédito pode ser frustrada não devido a uma suposta "escassez de poupança", mas porque 
os bancos podem considerar que o demandante não seria capaz de quitar seus compromissos no devido prazo por características da própria demanda que não pareça garantir a quitação da dívida.

Mesmo que houvesse a todo momento inovações que não pudessem ser implementadas por não conseguirem financiamento, o caso geral é que os empreendimentos produtivos guiam a direção do setor financeiro (Robinson, 1956). A expectativa de crescimento da demanda que propele a expansão dos processos produtivos é a mesma que faz com que instituições financeiras se disponham a financiar a produção. Em uma economia em que vigem expectativas de crescimento, caso haja uma restrição a oferta de financiamento, inovações financeiras são criadas, hábitos e instituições são moldadas, de forma a acomodar a demanda por financiamento (Robinson, 1956, Minsky, 2008). Assim, perspectivas de lucros elevados e um alto grau de confiança em tais perspectivas promovem a produção, da mesma forma que incentivam os agentes financeiros. A oferta de finança não é, assim, considerada como um gargalo que limita a taxa de investimento, mas é ela mesma determinada pelo ritmo em que os empreendimentos produtivos são criados.

\section{FINANÇAS, INOVAÇÃO E MUDANÇA ESTRUTURAL}

Como se argumentou, é inócuo buscar causalidade do tamanho do sistema financeiro para o crescimento econômico. O volume de financiamento é determinado pela demanda agregada e não o contrário. A conclusão de que o volume é menos relevante do que a destinação dos recursos é compartilhada por Ross Levine (2005). Mesmo que a quantidade da oferta de finanças não seja o gargalo principal à produção, a alocação dos recursos financeiros em determinados setores pode ser determinante para a taxa de crescimento econômico. O papel do sistema financeiro enquanto alocador de recursos em atividades mais produtivas é o principal argumento contemporâneo para sua capacidade de elevar a taxa de crescimento econômico. O desenvolvimento do sistema financeiro seria definido como uma melhora nos efeitos da informação, do enforcement e dos custos de transação, levando o sistema financeiro a exercer melhor suas funções. Levine $(1997,2005)$ sintetiza cinco funções do sistema financeiro: adquirir informação e alocar recursos, mobilizar poupança, exercer governança corporativa, facilitar a administração de risco, facilitar a troca de bens e serviços.

Um sistema financeiro desenvolvido produziria mais informação sobre as firmas e identificaria as melhores tecnologias de produção, ou os empreendedores mais capazes de iniciar novos bens ou processos. Após a realização do financiamento, o mercado financeiro poderia atuar no monitoramento das firmas, fortalecendo a governança corporativa. Ademais, o sistema financeiro possibilita melhor administração do risco como maior liquidez, hedging, e diversificação do investimento.

Desta perspectiva, o crescimento econômico proporcionado pelas instituições financeiras adviria de mudanças estruturais da economia possibilitadas por sua 
atuação. Indústrias incapazes de autofinanciar a expansão de sua produção encontrariam nas instituições financeiras o provedor do poder de compra necessário para prosseguir com seu investimento. As instituições financeiras seriam capazes de identificar as tecnologias mais eficientes e conceder-lhes empréstimos. A capacidade de identificar as melhores oportunidades tecnológicas garantiria às instituições financeiras desenvolvidas um papel fundamental no crescimento econômico.

O trabalho de Rajan e Zingales (1998) é expoente de tal perspectiva, em que se argumenta que em países com sistema financeiro desenvolvido, indústrias que dependem mais fortemente do financiamento externo terão taxas de crescimento relativamente mais elevadas. A dependência financeira de uma indústria seria motivada por fatores técnicos da indústria, como a escala mínima de produção, o tempo de gestação e maturação dos projetos, etc. $O$ desenvolvimento financeiro habilitaria empresas mais dependentes de financiamento externo a crescer mais aceleradamente, e por meio de tal mudança na estrutura produtiva, a taxa de crescimento seria acelerada.

Rajan e Zingales utilizam uma base de dados microeconômica para testar suas hipóteses, de modo que os efeitos agregados sobre o crescimento econômico dependem das características das indústrias relativamente mais dependentes do financiamento externo. Os autores demonstram que firmas mais jovens e do setor industrial são mais dependentes do financiamento externo. Assim, os autores utilizam um argumento "Schumpeteriano" de que firmas jovens são tipicamente inovadoras e possibilitam ondas de destruição criativa, elevando as taxas de crescimento agregado.

A evidência apresentada pelos autores é frágil do ponto de vista agregado, uma vez que não são esclarecidas as razões pelas quais empresas mais dependentes propiciam o crescimento econômico. Tal relação entre a dependência financeira e o crescimento da produtividade é proporcionado por llyina e Samaniego(2011) que evidenciam que indústrias com maior intensidade de $P \& D$ têm maior tendência à utilização de fundos externos. As indústrias que mais investem em P\&D teriam menor capacidade de contrair empréstimos, por não conseguirem alienar seus ativos, e maior dependência dos empréstimos dado o maior período de gestação dos projetos, o alto custo inicial dos projetos e o curto período para extração dos retornos do investimento. Por outro lado, tais indústrias teriam crescimento da produtividade superior às demais indústrias da economia, e seu crescimento relativo afetaria positivamente o crescimento econômico.

As retiradas da restrição de crédito seriam mais fortemente sentidas pelos setores intensivos em $P \& D$, afetando o crescimento da produção total por dois canais: crescimento mais acelerado da produtividade dentro do setor e a mudança estrutural que aumentaria a participação dos setores intensivos em $P \& D$ na economia. Ou seja, os mercados financeiros encorajariam o crescimento por alocar recursos em setores com mais elevada tecnologia e maior crescimento da produtividade. Em suma, em países com sistema financeiro desenvolvido, indústrias 
intensivas em P\&D crescem mais rapidamente, induzindo o aumento da produtividade e do crescimento.

Ilyina e Samaniego (2012) apresentam um modelo de equilíbrio geral em que a retirada das restrições financeiras possibilitam esta mudança estrutural na direção de setores mais intensivos em P\&D. Apesar disso, os autores ressaltam que as taxas de mudança estrutural podem ser afetadas caso existam diferenças no risco entre as indústrias e os agentes não sejam neutros ao risco, hipótese não considerada por seu modelo (Ilyina e Samaniego, 2012, p 22). Agentes neutros ao risco estão dispostos a alocar seu investimento no projeto mais arriscado, que permite maiores retornos. Ao desconsiderar a incerteza especialmente elevada envolvida nos empreendimentos inovadores, modelos de equilíbrio geral como o de llyina e Samaniego (2012) superestimam a real capacidade do setor financeiro em alocar os recursos nos setores mais promissores do ponto de vista tecnológico, especialmente em economias subdesenvolvidas.

Em contraposição à perspectiva dos modelos de equilíbrio geral em que a eliminação da restrição financeira é suficiente para que as indústrias intensivas em P\&D aumentem sua participação no produto, Carlota Perez (2004) apresenta uma visão de longo prazo da relação entre finanças e desenvolvimento tecnológico. Desta perspectiva, as grandes inovações tecnológicas têm um profundo impacto na reestruturação das esferas técnicas, sociais e institucionais da economia criando paradigmas tecnológicos.

Tais mudanças fazem com que certas indústrias, mais intimamente ligadas à exploração do paradigma tecnológico vigente ganhem crescente parcela da produção, enquanto outras indústrias, associadas com antigos paradigmas veem sua influência declinar. O financiamento das atividades econômicas seguiria critérios semelhantes àqueles adotados pelos demais setores produtivos (Carlota Perez, 2004, p 801). Isto é, o paradigma tecnológico de cada revolução tecnológica influencia simultaneamente empreendedores e banqueiros, gestores e inovadores, investidores e consumidores. Tal paradigma constitui um modelo de pensamento comum dos agentes econômicos durante todo o período de propagação de um grupo de tecnologias.

No contexto de um certo paradigma tecnológico já estabelecido, é razoável supor que as instituições financeiras compreendam as transformações tecnológicas de larga escala e direcionem as finanças para atividades ligadas ao paradigma. Apesar disso, é notável a importância do financiamento público para a emergência de novas tecnologias transformadoras (Mazzucato, 2013). Ademais, inovações incrementais, fruto de investimentos localizados em $P \& D$, que alteram rotinas e criam processos e produtos específicos são mais dificilmente identificados pelas instituições financeiras. Há diversos motivos para crer que o investimento em atividades inovadoras envolve maiores incertezas para o empreendedor, assim como riscos mais elevados para as instituições financeiras. A maior incerteza implica uma exigência de retorno mais elevada, seja do próprio empreendedor, ou da instituição financeira disposta a conceder um financiamento. 
Como já observado por Arrow (1962), as características do investimento em inovação (invenção, nos termos do autor) invalidam os pressupostos necessários para que a alocação de recursos seja feita de forma eficiente pelo mercado. Arrow (1962) argumenta a alocação ótima de recursos falha na medida em que há indivisibilidades, inapropriabilidades e incerteza. Mazzucato (2013) explicita que investimento em inovação é caracterizado por três características chave: seu caráter acumulativo, incerto e coletivo. Dadas essas características o investimento em inovação exige finanças pacientes, de longo prazo e comprometidas com o objetivo do investimento.

No que diz respeito à apropriabilidade, o conhecimento de como produzir novos bens e serviços é não rival, ou seja, o uso dele por uma firma não impede o uso por outra. Além disso, o conhecimento não é completamente excluível, de modo que os retornos do investimento em conhecimento não podem ser completamente apropriados pela firma que leva a cabo o investimento em pesquisa e desenvolvimento. Ademais, grande parte do investimento em P\&D custeia os gastos com salários de pesquisadores. Uma vez que parte do conhecimento gerado pelas firmas é tácito, ou não codificável, ele está embarcado no capital humano dos funcionários da firma, de modo que caso os empregados deixem a empresa ele pode ser perdido. Assim, uma vez que a renda do conhecimento não seria completamente apropriável pela empresa, o investimento em pesquisa se situaria em nível abaixo do ótimo social. Com esta justificativa, foram criados os direitos de propriedade intelectual, que buscam reforçar a apropriabilidade dos investimentos em P\&D.

O investimento em inovação é uma aposta no futuro sujeita à incerteza, não a um risco calculável. Pela própria definição do processo de pesquisa, o produto do investimento em $P \& D$ não pode ser previsto diretamente pelos seus insumos (Arrow, 1962). Assim, no contexto do processo inovador, a incerteza deve ser entendida no sentido utilizado por Frank Knight, isto é, o preço e a performance das novas tecnologias não podem ser conhecidos antecipadamente. Assim como não são conhecidas as preferências específicas do consumidor e suas práticas diante de um produto ainda não criado.

Se o próprio investimento em inovação é constrangido por suas características específicas, o financiamento a tais atividades é ainda mais dificultado. O caráter incerto e cumulativo da inovação leva o financiamento de tais atividades ser mais complexo devido ao (1) aprofundamento das assimetrias de informação; (2) a prevalência do risco crescente; (3) menor tempo de vida de empresas inovadoras.

O problema da assimetria de informação no contexto do financiamento da inovação surge pelo fato de que o tomador de empréstimo tem maior informação sobre a capacidade de sua inovação ser bem-sucedida que o emprestador. Como afirmam Hall e Lerner (2010), o prêmio externo dos investimentos em P\&D são superiores àqueles exigidos pelos demais tipos de investimento, pois o mercado financeiro tem mais dificuldade em avaliar projetos de longo prazo e alto risco. A assimetria de informação se reflete também na dificuldade de monitorar a implantação dos projetos de $P \& D$, uma vez que a criação de ativos tangíveis é lenta, 
o que exacerba os problemas de agência no monitoramento do investimento por parte do emprestador.

O longo prazo dos empréstimos necessários para o investimento em $P \& D$ faz com que empresas intensivas em P\&D sejam tipicamente alavancadas, o que leva a estruturas de capital mais arriscadas. O crescimento do endividamento em proporção do capital próprio eleva o risco do negócio, limitando também o crescimento da firma (Minsky, 2008). O crescimento das firmas é limitado, então pela própria estrutura de capital exigida para a consecução do investimento em inovação.

Em grandes empresas, a condução de pesquisas e desenvolvimento têm seus riscos mitigados pela diversificação de diversos projetos, cada um deles com pequena parcela das receitas (Arrow, 1962, p 616). Empresas estabelecidas têm também uma maior proporção de ativos fixos que podem ser utilizados como colateral para a tomada de empréstimos, especialmente em mercados de crédito pouco desenvolvidos. Já para as firmas menores, é difícil a criação de colaterais para empréstimos, pois seus ativos mais relevantes estão relacionados à inovação proposta, ou a rotinas e conhecimentos tácitos.

Por todos estes motivos, o prêmio de financiamento externo em empresas inovadoras é mais elevado que nas demais empresas. Ao contrário do que é apresentado por autores como Rajan e Zingales (1998) e llyina e Samaniego (2012), o que se poderia prever é uma subalocação de financiamento nas atividades inovadoras. A escassez de financiamento à inovação é o que de fato tem se apresentado, não devido à escassez de recursos a serem investidos, mas à inadequação dos mecanismos de mercado para alocarem os recursos na direção esperada pelos modelos de crescimento.

\section{CONCLUSÃO}

Mesmo aqueles que acreditam que o sistema financeiro é apenas uma resposta ao crescimento, concordam que uma infraestrutura financeira é condição necessária para que o desenvolvimento econômico aconteça. O desenvolvimento econômico depende da mobilização da atividade humana para transformação de antigos meios de produção e das relações sociais associadas a eles. Apesar de ser condição para o desenvolvimento econômico, o impulso inicial para a mobilização dos recursos não parte do setor financeiro. Mesmo para Schumpeter, o banqueiro teria o papel de autorizar e não o de levar a cabo a inovação conducente ao desenvolvimento. Nas palavras de Schumpeter, o banqueiro, enquanto éforo do sistema econômico, permite a flexibilização da atividade econômica, mas não dá início ao processo de inovação e transformação econômica.

Da máxima de Joan Robinson: "where enterprise leads money follows" extrai-se que as finanças são direcionadas pelos mesmos impulsos que o investimento, isto é, setores avaliados pelos mercados como mais promissores recebem maior fluxo de capital. Os planos de investimento são limitados pela oferta de finança, no sentido de que em um mundo de incerteza, emprestadores devem prover garantias, sejam elas 
reais, ou referentes a perspectivas de lucros futuros. A oferta de finança não é limitada pela poupança, mas pela inexistência de tomadores de empréstimo considerados solventes pelas instituições financeiras. Ao considerar que o sistema financeiro é capaz de criar crédito, desde que haja tomadores de empréstimos considerados solventes, não é o volume da oferta de finanças que constrange o desenvolvimento, mas a distribuição de tais finanças.

Apesar da possibilidade da criação de crédito pelo sistema bancário, o desenvolvimento é condicionado à alocação do crédito nas atividades mais inovadoras. Tais atividades, intensivas em $P \& D$, sofrem com a escassez de financiamento, devido às características intrínsecas a tais setores. A inovação implica incertezas que estendem o prazo de maturação dos projetos e eleva o risco das empresas. Ao desconsiderar tais riscos crescentes é comum que modelos de equilíbrio geral apontem que a retirada das restrições financeiras levaria ao maior crescimento econômico. O que se deixa de considerar é a própria demanda por financiamento, a qual não é avaliada igualmente pelas instituições financeiras.

Investimentos intensivos em P\&D envolvem incertezas e comprometimento superiores a investimentos tradicionais. Para tais investimentos é exigido uma taxa de retorno superior, seja este investimento realizado apenas com fundos próprios ou com financiamento externo. A dependência de financiamento externo é mais frequente nos investimentos em $P \& D$, mas é também mais difícil dadas as características de tais investimentos. Por estes e outros motivos, a liberalização financeira não é suficiente para a convergência tecnológica e das taxas de crescimento.

Mecanismos que permitam a realocação rápida do capital produtivo para atividades inovadoras são condição necessária para o desenvolvimento econômico. Por outro lado, o crescimento do sistema financeiro de mercado não é condição suficiente para que o capital se direcione para as atividades inovadoras. Se o mercado financeiro pode corrigir certas falhas de mercado, ele mesmo é sujeito a tais falhas. Mais do que falhas de mercado, a mudança estrutural necessária para o desenvolvimento, no sentido schumpeteriano, com a alocação de recursos para setores mais inovadores, não é garantida pela simples liberalização financeira, ou pelo crescimento do setor financeiro.

\section{REFERÊNCIAS BIBLIOGRÁFICAS}

Aghion, Philippe, Peter Howitt, and David Mayer-Foulkes. "The effect of financial development on convergence: Theory and evidence." The Quarterly Journal of Economics 120.1 (2005): 173-222.

Arcand, Jean Louis, Enrico Berkes, and Ugo Panizza. "Too much finance?." Journal of Economic Growth 20.2 (2015): 105-148.

Arestis, Philip, and Panicos Demetriades. "Financial development and economic growth: assessing the evidence." The Economic Journal 107.442 (1997): 783-799. 
Arrow, Kenneth. "Economic welfare and the allocation of resources for invention." The rate and direction of inventive activity: Economic and social factors. Princeton University Press, 1962. 609-626.

Caner, Asena. "Does Financial Liberalization Help the Poor?." Macroeconomics, Finance and Money. Palgrave Macmillan, London, 2010. 224-236.

Carlota, Perez. "Finance and technical change: A long-term view/H. Hanusch and A. Pyka (eds.). The Elgar Companion to Neo-Schumpeterian Economics." (2004): 77-99.

Dantas, A, Kertsnetzky, j., Prochnik, V. "Empresa, Indústria e Mercados". Em: Hasenclever, Lia, and D. J. Kupfer. Economia industrial. Elsevier Brasil, 2013.

Dosi, Giovanni. "Finance, innovation and industrial change." Journal of Economic Behavior \& Organization 13.3 (1990): 299-319.

Gershenkron, A. "Economic Backwardness in Historical Perspective. A Book of Essays. Frederick A." (1962).

Gersovitz, Mark. "Saving and development." Handbook of development economics 1 (1988): 381-424.

Hall, Bronwyn $\mathrm{H}_{\text {., }}$ and Josh Lerner. "The financing of R\&D and innovation." Handbook of the Economics of Innovation. Vol. 1. North-Holland, 2010. 609-639.

Ilyina, Anna, and Roberto Samaniego. "Structural change and financing constraints." Journal of Monetary Economics 59.2 (2012): 166-179.

Ilyina, Anna, and Roberto Samaniego. "Technology and financial development." Journal of Money, Credit and Banking 43.5 (2011): 899-921.

King, Robert G., and Ross Levine. "Finance and growth: Schumpeter might be right." The quarterly journal of economics 108.3 (1993): 717-737.

Kregel, Jan. "Trying to serve two masters: The Dilemma of Financial Regulation". Em: Cynamon, Barry Z., Steven Fazzari, and Mark Setterfield, eds. After the great recession: the struggle for economic recovery and growth. Cambridge University Press, 2012.

Krüger, Jens J. "Productivity and structural change: a review of the literature." Journal of Economic Surveys 22.2 (2008): 330-363.

Lavoie, Marc. "Post-Keynesian economics: new foundations". Edward Elgar Publishing, 2014.

Law, Siong Hook, and Nirvikar Singh. "Does too much finance harm economic growth?." Journal of Banking \& Finance 41 (2014): 36-44. 
Levine, Ross. "Finance and growth: theory and evidence." Handbook of economic growth 1 (2005): 865-934.

Levine, Ross. "Financial development and economic growth: views and agenda." Journal of economic literature 35.2 (1997): 688-726.

Lucas Jr, Robert E. "On the mechanics of economic development." Journal of monetary economics 22.1 (1988): 3-42.

Mazzucato, Mariana. "Financing innovation: creative destruction vs. destructive creation." Industrial and Corporate Change 22.4 (2013): 851-867.

McKinnon, R.I.. 1973. "Money and capital in economic development". Brookings Institution,

McKinnon, Ronald I. "The order of economic liberalization: Financial control in the transition to a market economy." JHU Press, 1993.

Minsky, Hyman P. "Stabilizing an unstable economy". Vol. 1. New York: McGraw-Hill, 2008.

Possas, Mario Luiz. "Demanda efetiva, investimento e dinâmica." Revista Economia Comtemporânea, Rio de Janeiro 3.2 (1999).

Rajan, Raghuram G., and Luigi Zingales. "Financial dependence and growth". No. w5758. National bureau of economic research, 1998

Robinson, Joan. "The generalisation of the general theory and other essays." Springer, 1979.

Schumpeter, Joseph A. "Teoria do desenvolvimento econômico". Rio de Janeiro: Fundo de Cultura, 1961.

Shaw, E. S. "Financial deepening in economic development". Oxford University Press, 1973

Stein, Howard. "Institutions and Finance in Developing Countries: Challenges to Orthodoxy." Macroeconomics, Finance and Money. Palgrave Macmillan, London, 2010. 295-310.

Studart, Rogerio. "Investment finance in economic development". Routledge, 1995.

Taylor, John B. "Discretion versus policy rules in practice". In: Carnegie-Rochester conference series on public policy. North-Holland, 1993. p. 195-214

Woodford, Michael. "Interest Rates and Prices". Princeton University Press, 2003. 
Zysman, John. "Governments, markets, and growth: financial systems and the politics of industrial change". Vol. 15. Cornell University Press, 1983. 